\title{
Resveratrol normalizes hyperammonemia induced proinflammatory and pro-apoptotic conditions in rat brain
}

\begin{abstract}
Chronic liver failure (CLF) led hyperammonemia (HA) is known to develop a metabolic brain disorder known as hepatic encephalopathy (HE). TNF- $\alpha$ is now considered responsible for mounting neurological complications associated with HA/HE. However, the mechanism that connects inflammation and neuroexcitotoxicity is not yet clear. Resveratrol (RSV) is a natural antioxidant and known to mediate its therapeutic actions mainly by scavenging Reactive oxygen species (ROS). RSV is predicted to modulate many cellular targets as well; however, there is little information on its neuroprotective roles. This article describes the effect of RSV treatment on the expression profiles of TNF- $\alpha$,

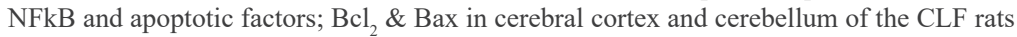
(induced by administration of $100 \mathrm{mg}$ thioacetamide i.p. for 10days) confirming moderate grade HA. A significant increase in mRNA level of TNF- $\alpha(p<0.001)$ in both of the brain regions (cerebral cortex and cerebellum) of HA rats was observed This was consistent with a similar enhancement in the level of NFkB, a transcription factor for TNF- $\alpha$ synthesis, and thus, suggests induction of TNF- $\alpha$ led inflammation in the brain during persistent HA. A significant decline in $\mathrm{Bcl}_{2}$ level $(\mathrm{p}<0.001)$ with a significantly enhanced level of Bax further suggested a neurodegenerative condition in those brain regions of the HA rats. Moreover, post treatment of those HA rats, with $10 \mathrm{mg} / \mathrm{Kg}$ b.w. RSV for a week, was found to bring all the factors towards their normal level in both the brain regions. The finding suggest that RSV is able to ameliorate moderate HA induced TNF- $\alpha$ led inflammatory cascade and proapoptotic neurodegenerative condition in the rat brain primarily by modulating expression of the inflammatory and apoptotic factors.
\end{abstract}

Keywords: hyperammonemia, neuro inflammation, moderate he, tnf- $\alpha$, apoptosis, cortex, cerebellum
Volume 4 Issue 2 - 2016

\author{
Archita Khanna, Surendra K Trigun \\ Department of Zoology, Banaras Hindu University, India
}

Correspondence: Surendra K Trigun, Department of Zoology, Institute of Science, Banaras Hindu University, Varanasi-221005, India,Tel 9I-542-6702523, Email sktrigun@bhu.ac.in

Received: July 31, 2016 | Published: August 26, 2016

\section{Introduction}

Ammonia neurotoxicity is considered responsible for development of a serious nervous system disorder called hepatic encephalopathy (HE). This situation arises mainly due to liver dysfunction led hyperammonemia (HA). HE is characterized by the neuropsychiatric manifestations related to motor dysfunction, memory impairment, and deranged sleep-awake cycle. ${ }^{1,2}$ Since HE affects the quality of life of the patients, it is important to develop effective therapeutic strategy against HE. This necessitates understanding the neuro-chemistry of HA pathogenesis.

Since ammonia crosses the blood brain barrier easily, prolonged HA condition, a common situation during chronic liver failure (CLF), is likely to maintain increased ammonia concentration in brain. ${ }^{3,4}$ The information, mainly derived from the cell culture system and from animal models with acute HE, suggest that the increased brain ammonia level mainly drives astrocytes to undergo significant morpho-pathological changes and also over activates glutamateNMDA receptor (N-Methyl-D-Aspartate Receptor) pathway in the post-synaptic neurons. ${ }^{1,5-7}$ Moreover, NMDAR inhibition could not be translated into prevention of ammonia neurotoxicity, mainly because threshold glutamate-NMDAR activation is necessary for normal neurological functions including higher order brain functions and normal synaptic activity.

During recent past, "TNF theory" (Tumor necrosis factor) of HE pathogenesis could draw much attention due to a close association between the level of TNF- $\alpha$ and ammonia in the brain of CLF patients with HE. ${ }^{8}$ Later studies have also emphasized significant involvement of TNF- $\alpha$ and other cytokines in HE to the extent that these cytokines could be used as markers for encephalopathy grading. ${ }^{4,9-13}$

It is now evident that the microglia and astroglia cells in brain synthesize TNF- $\alpha$ to regulate higher order brain functions and astrocyte induced synaptic strengthening. ${ }^{14-17}$ However, when produced in higher amounts during neuropathology, they are known to potentiate glutamate induced cytotoxicity by inhibiting glutamate transport to the glial cells from the synaptic cleft.12,16-19 Even development of MHE has been described to be dependent more on enhanced inflammatory markers than the severity of CLF or HA in the CLF patients. ${ }^{20}$ Moreover, some findings from in vitro studies suggest that resveratrol treatment could prevent ammonia toxicity in astroglial cells by normalizing ROS/RNS level. ${ }^{12,21,22}$ Thus, hinting towards a significant role of resveratrol in ameliorating ammonia toxicity. However, the mechanism by which resveratrol does so is unclear.

Resveratrol (3, 3, 4'-trihydroxy-Trans stilbene), a natural polyphenol, is found in a number of dietary sources such as grapes, berries, and red wine. ${ }^{23-25}$ It acts as an effective cardioprotector, anti-aging, and anti-carcinogenic agent in vivo. ${ }^{12,26-28}$ Some reports also suggest that this natural polyphenol exerts neuroprotection during certain neurodegenerative challenges ${ }^{12,26-28}$ mainly due to its ROS scavenging properties and/or by activating some antioxidant enzymes. Some recent observations, mainly derived from in vitro studies, suggest that ammonia induced impaired glutamatergic communication in astroglial cells could be recovered with resveratrol treatment ${ }^{29}$ Since astroglia cells are the main source of inflammatory 
cytokines, it is argued that resveratrol could also prevent inflammatory mechanisms implicated in impaired glutamate transport during ammonia neurotoxicity. And if it does so, then this polyphenol must be able to down regulate apoptotic mechanism which otherwise becomes upregulated during such challenges. ${ }^{30-32}$

Thus, to investigate whether resveratrol is able to modulate inflammation-apoptosis pathway in the HA brain, the expression profiles of TNF- $\alpha$ (a proinflammatory marker), NFkB (a transcriptional regulator of inflammatory cytokines) and intrinsic apoptotic factors $\left(\mathrm{Bcl}_{2} / \mathrm{Bax}\right)$ were examined in the cortex and cerebellum (the two susceptible brain regions) of the CLF rats with moderate grate HA.

\section{Material and methods}

\section{Chemicals}

All chemicals used were of analytical grade purchased from E-Merck and Sisco research Laboratory, Mumbai (India) except N,N'-methylenebisacrylamide, Acrylamide, N,N,N'N'tetramethylethylenediamine (TEMED), phenylmethylsulphonyl fluoride (PMSF), Ponceau S and bromophenol blue, which were purchased from Sigma-Aldrich, USA. Primary antibodies used were supplied from the following companies: rabbit polyclonal $\mathrm{Bcl}_{2}$ and Bax from Cell Signaling Technology and rabbit monoclonal $\beta$-actin from Sigma Aldrich. Goat anti-Rabbit horseradish peroxidase (HRP) conjugated secondary antibodies were supplied from Genei. ECL western blotting detection kit was procured from Thermo Scientific. The trans-Resveratrol was supplied from the Cayman chemicals company.

The following molecular biology kits and reagents were used: TRI reagent and DEPC (Sigma Aldrich, Revert Aid first strand cDNA synthesis kit (Thermo Scientific, Lithuania), TURBO DNAfree $^{\mathrm{TM}}$ (Ambion RNA by Life Technologies ${ }^{\mathrm{TM}}$, USA) Maxima SYBR Green/ ROX qPCR master mix 2X (Thermo Scientific). The primers used in the present study were synthesized by Eurofins Genomics India Pvt. Ltd. The rat gene specific primers used were: Bax (Forward 5'- GATCATGAAGACAGGGGCCTT-3'; Reverse 5'-CCTGGATGAAACCCTGTAGCA-3'); $\mathrm{Bcl}_{2}$ (Forward 5'-ACACCAGAATCAAGTGTTCGT-3'; Reverse 5'-TGCATTCTTGGATGAAGGGGT-3'); TNF$\alpha$ (Forward 5'TCATCAGTTCCATGGCCCAGAC-3'; Reverse 5'-GGTTTGCTACGACGTGGGCTA-3'); NFkB (Forward 5'- GCGTTTCCGTTACAAGTGCGAGG-3'; Reverse 5'-CCCCAGGAATACTGCCTGCAGAG-3'). The primers were designed using the Fast PCR 6.1 software.

\section{Animals}

The adult male albino rats weighing $130-160 \mathrm{~g}$, used in this study, were fed the recommended diet and maintained on $12: 12 \mathrm{~h}$ light: dark cycle, in an animal house, as per recommendations from the institutional animal ethical committee (IAEC) of Banaras Hindu University, for the care and use of the laboratory animals.

\section{Development of chronic liver failure (CLF)/HA and treatment schedule}

The CLF/HA model of neuroinflammation in adult male albino rats was developed by the administration of thioacetamide (TAA) as standardized in our lab. ${ }^{33}$ The rats were divided into three groups with six rats in each. Group A: control (C), administered with $0.9 \% \mathrm{NaCl}$ i.p, once daily for 10days; Group B: Hyperammonemia (CLF/HA), administered with $100 \mathrm{mg} / \mathrm{Kgbw}$ TAA (prepared in $0.9 \% \mathrm{NaCl}$ ) i.p once daily for 10days; Group C: CLF/HA + Resveratrol (CLF/HA + RSV) administered with $10 \mathrm{mg} / \mathrm{Kgbw}$ Resveratrol i.p once daily, dissolved in $1 \% \mathrm{DMSO}$, starting from $8^{\text {th }}$ day onwards till $14^{\text {th }}$ day. The Resveratrol was administered $4 \mathrm{~h}$ after the TAA treatment. The selected dose of Resveratrol was able to recover TAA induced neurobehavioural deficit in the rats. After $24 \mathrm{~h}$ of the last dose given, all the rats were sacrificed on $15^{\text {th }}$ day. To confirm the hyperammonemic condition, ammonia assay was performed in the pooled serum of all the six rats from control and HA groups. The cortex and cerebellum was dissected out and stored at $-80^{\circ} \mathrm{C}$ for further studies.

\section{Preparation of cortex and cerebellum extracts}

Cerebral cortex and cerebellum extracts were prepared in 0.02 $\mathrm{M}$ Tris- $\mathrm{Cl}(\mathrm{pH}$ 7.4) containing protease inhibitors. Extracts were centrifuged at $35,000 \mathrm{~g}$ for $45 \mathrm{~min}$ at $4{ }^{\circ} \mathrm{C}$. The supernatant collected was used for the ammonia assay. Protein content was determined by the method of Lowry et al., ${ }^{34}$

Mitochondria-free tissue extract was prepared in an extraction medium consisting of $400 \mathrm{mM}$ sucrose, $0.2 \mathrm{mM}$ benzamidine, $1 \mathrm{mM}$ EDTA, 0.1mM phenylmethylsulfonyl fluoride (PMSF) ( $\mathrm{pH} 7.4)$, and $0.02 \%$ heparin. Initially, the extracts were centrifuged at $12,000 \times \mathrm{g}$ for $15 \mathrm{~min}$ and finally at $19,000 \times \mathrm{g}$ for $40 \mathrm{~min}$ at $4^{\circ} \mathrm{C}$ to obtain cytosolic fractions. The protein content in the extract was estimated by Lowry method as mentioned earlier.

Ammonia assay: The ammonia assay was performed using a kit supplied by Sigma-Aldrich, USA. The serum as well as cortex and cerebellum extract were deproteinized in 1/5volume of ice-cold 100g/ $\mathrm{L}$ Trichloroacetic acid and kept on ice for $15 \mathrm{~min}$. After centrifugation at $15,000 \mathrm{Xg}$ for $15 \mathrm{~min}$ at $4^{\circ} \mathrm{C}$, the supernatants were neutralized with $2 \mathrm{M} \mathrm{KHCO} 3$, centrifuged and used for ammonia assay. The quantification of ammonia involved measuring the rate of conversion of $\alpha$-ketoglutarate to glutamate catalyzed by glutamate dehydrogenase in the presence of ammonia. The decrease in O.D. at $340 \mathrm{~nm}$ was recorded.

The $1 \mathrm{~mL}$ reaction mixture, contained $50 \mu \mathrm{L}$ samples, $3.4 \mathrm{mM}$ $\alpha$-ketoglutarate and $0.23 \mathrm{mM}$ reduced NADPH in water. The mixture was incubated for $5 \mathrm{~min}$ at $18-35^{\circ} \mathrm{C}$ and reaction was started by the addition of suitably diluted GDH. Initial and final (at $5 \mathrm{~min}$ ) O.D. at $340 \mathrm{~nm}$ was used to calculate concentration of ammonia in mM.

Western blotting: Briefly, $100 \mu \mathrm{g}$ of cytosolic protein was loaded in each lane and subjected to $10 \%$ denaturing polyacrylamide gel electrophoresis at constant voltage of 100volts for 2 hours followed by transferring the protein bands on nitrocellulose membrane over night at $50 \mathrm{~mA}$ at $4{ }^{\circ} \mathrm{C}$. Efficiency of Protein transfer was checked by Ponceau S staining. The membrane was then placed in a blocking solution ( $5 \%$ non fat dried milk in $1 \mathrm{X}$ PBS) for $2 \mathrm{~h}$. The membrane was processed for immunodetection of $\mathrm{Bcl}_{2}$ antibody (1:1000) and $\mathrm{Bax}$ antibody (1:500). HRP-conjugated secondary antibody was used for final detection of the respective proteins using ECL western blotting detection kit. For loading control, monoclonal anti- $\beta$-actin peroxidase antibody $(1: 10,000)$ was used. The normalized densitometric values of each protein vs $\beta$-actin, was recorded using gel densitometry software Alpha Imager 2200.

RNA isolation and cDNA synthesis: Total RNA from cortex and cerebellar extracts was isolated using TRI reagent following the manufacture's protocol. Briefly, the homogenate prepared in $1 \mathrm{~mL}$ TRI reagent was centrifuged at $12,000 \mathrm{~g}$ for $10 \mathrm{~min}$ at $4^{\circ} \mathrm{C}$ and supernatant was collected. Chloroform was added $(0.2 \mathrm{~mL})$ to the supernatant and vortexed. After $3 \mathrm{~min}$, the tube was centrifuged at $12,000 \mathrm{Xg}$ for 
$10 \mathrm{~min}$, at $4^{\circ} \mathrm{C}$. The centrifugation separated the mixture into 3 phases, out of which the colorless upper aqueous phase containing RNA was collected and $0.5 \mathrm{~mL}$ isopropanol was added to it. After $5 \mathrm{~min}$, the tube was again centrifuged at $12,000 \mathrm{X}$ for $10 \mathrm{~min}$, at $4^{\circ} \mathrm{C}$. The RNA precipitated out in the form of a pellet at bottom of the tube and was washed in $1 \mathrm{~mL} \mathrm{75 \%}$ ethanol. After air drying the RNA pellet, it was dissolved in $60 \mu \mathrm{L}$ DEPC treated water by repeated pipetting. The dissolved RNA pellet was subjected to DNase treatment (DNA freeAmbion) to remove any sort of DNA contamination. The total RNA yield was determined and quality assessed by agarose formaldehyde RNA gel electrophoresis.

The RNA samples with an $\mathrm{A}_{260} / \mathrm{A}_{280}$ ratio of 1.8-2.0 were used in the cDNA synthesis reaction. RevertAid first strand cDNA synthesis kit was used for cDNA synthesis. The reaction mixture consisted of $4 \mu \mathrm{g}$ RNA, $1 \mu \mathrm{L}$ random hexamer primer, made up to $12 \mu \mathrm{L}$ with DEPC treated water. The mixture was gently mixed, centrifuged briefly and the following components were added; $4 \mu \mathrm{L}$ of $5 \mathrm{X}$ reaction buffer, $1 \mu \mathrm{L}$ of RiboLock ${ }^{\mathrm{TM}}$ Ribonuclease Inhibitor $(20 \mathrm{U} / \mu \mathrm{L}), 2 \mu \mathrm{L}$ of $10 \mathrm{mM}$ dNTP mix, $1 \mu \mathrm{L}$ of reverse transcriptase to make a final volume of $20 \mu \mathrm{L}$. The components were mixed gently and incubated for $5 \mathrm{~min}$ at $25^{\circ} \mathrm{C}$ followed by cDNA strand synthesis for $60 \mathrm{~min}$ at $42^{\circ} \mathrm{C}$. The reaction was terminated by heating at $72^{\circ} \mathrm{C}$ for $5 \mathrm{~min}$. The cDNA was stored at $-80^{\circ} \mathrm{C}$.

Real time (qPCR): The real time qPCR was done with an $\mathrm{ABI}$ Prism 7500 Sequence Detection System (PE Applied Biosystems, CA, USA). The PCR reaction mixture of $(20 \mu \mathrm{L})$ consisted of $1 \mu \mathrm{L}$ of sample cDNA (diluted $1: 10$ ), $1 \mu \mathrm{L}$ of $10 \mathrm{pM}$ of forward and reverse primers and $10 \mu \mathrm{L}$ of $2 \mathrm{X}$ Thermo Scientific SYBR Green/ROX qPCR Master Mix and brought to final volume with RNase free water.

PCR condition was: $95^{\circ} \mathrm{C}$ for $30 \mathrm{sec}$, followed by 40 cycles at $95 \mathrm{C}$ for $5 \mathrm{sec}$, and $60^{\circ} \mathrm{C}$ for $20 \mathrm{sec}$. Real-time PCR data was analyzed using the $\Delta \Delta \mathrm{C}_{\mathrm{T}}$ method, normalizing the $\mathrm{Ct}$ values of the indicated gene to the $\mathrm{Ct}$ values of GAPDH relative to a control sample.

Statistical analysis: The statistical analysis of experimental data was done by applying Student's t test, expressed as mean \pm SD and $\mathrm{P}<0.05$ was taken as the level of significance between the control and experimental sets.

\section{Results}

\section{Development of chronic liver failure/ hyperammonemia}

The HA condition due to TAA induced CLF was evident from a $~ 2$ $\mathrm{x}$ increase $(\mathrm{P}<0.01)$ in serum ammonia level of $\mathrm{CLF} / \mathrm{HA}$ rats (Figure 1a). Also, as depicted in Figure 1b\&c, as compared to the control group rats, the level of ammonia was significantly increased $(\mathrm{P}<0.05)$ in the cortex and in the cerebellum of CLF/HA rats. These findings confirm the induction of chronic liver failure led HA condition, both in the blood and in the susceptible brain regions.

\section{Effect of resveratrol on inflammatory factors: TNF- $\alpha$ and NF-KB}

Development of neuroinflammation is considered an important marker for HA in the brain. Neuroinflammation was monitored by measuring the transcript level of neuroinflammatory markers TNF- $\alpha$ and NF- $\mathrm{kB}$. According to Figure $2 \mathrm{a} \& \mathrm{~b}$, as compared to the control group rats, a significant increase $(\mathrm{P}<0.01)$ in the TNF- $\alpha$ transcript in cortex and cerebellum of CLF/ HA rats was observed. A similar pattern was observed for NF- $\kappa B$ transcript (Figure $3 a \& 3 b$ ), which showed significantly enhanced levels $(\mathrm{P}<0.001)$ in both the brain regions of the HA rats. However, the enhanced levels of both the neuroinflammatory markers, TNF- $\alpha$ and NF- $\mathrm{kB}$, were restored back to their normal levels in the HA rats treated with RSV.
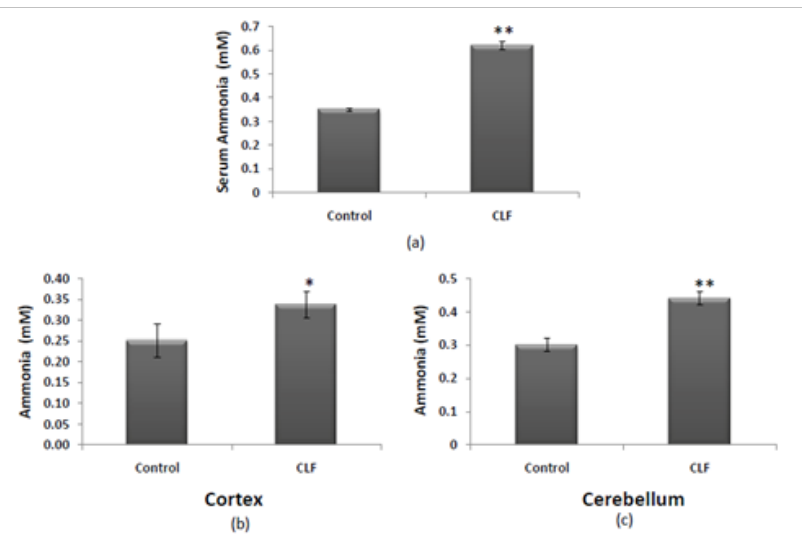

Figure I Effect of TAA treatment on ammonia level in serum (a), cortex (b) and cerebellum(c). Values are represented as mean \pm SD where $n=4 ; * P<0.05$; $* * P<0.01$; (control versus CLF), CLF: chronic liver failure.


Figure 2 Expression of TNF- $\alpha$ in cerebral cortex (a) and cerebellum (b) of control, $\mathrm{HA}$ and $\mathrm{HA}+\mathrm{RSV}$ treated rats. Cycle threshold value of TNF- $\alpha$ mRNA level was normalized with the cycle threshold value of Gapdh for each sample to give a relative quantity of the mRNA expression by $2-\mathrm{ddCt}$. Values are represented as mean \pm SD from 4 repeats; Gapdh was taken as the internal control. **P<0.0I; (control versus HA) \#P<0.05; \#\#P<0.0I; (HA versus HA+RSV), HA: Hyperammonemia, HA+RSV: Hyperammonemia + Resveratrol.
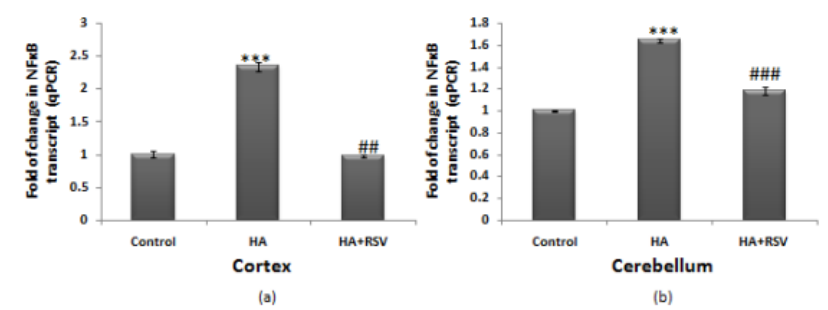

Figure 3 Expression of NF- $\kappa B$ gene in cerebral cortex (a) and cerebellum (b) of control, $\mathrm{HA}$ and $\mathrm{HA}+\mathrm{RSV}$ rats. Cycle threshold value of NF- $\kappa B$ RNA level was normalized with the cycle threshold value of Gapdh for each sample to give a relative quantity of the mRNA expression by 2-ddCt. Values are represented as mean \pm SD from 4 repeats; Gapdh was taken as the internal control. ***P<0.00I; (control versus HA) \#P $<0.0$ I; \#\# 100.001 ; (HA versus HA+RSV), HA: Hyperammonemia, HA+RSV: Hyperammonemia + Resveratrol.

\section{Effect of resveratrol on $\mathrm{BCl}_{2}$ and $\mathrm{Bax}$ expression}

Looking at the ratio of $\mathrm{Bcl}_{2} / \mathrm{Bax}$ is the most effective way to determine the susceptibility of cells for undergoing apoptosis. According to Figure $4 \mathrm{a} \& \mathrm{c}$, it is evident that the expression level of $\mathrm{Bcl}_{2}$ is significantly declined in both, the cortex $(\mathrm{P}<0.001)$ and the cerebellum $(\mathrm{P}<0.01)$, as compared to that observed in the control 
group rats. The expression level of Bax (Figure 5a\&c) was also found to be significantly enhanced in the cortex $(\mathrm{P}<0.001)$ and in the cerebellum $(\mathrm{P}<0.01)$ of the HA rats, as compared to the control group of rats; resulting in a significant decline in the $\mathrm{Bcl}_{2} / \mathrm{Bax}$ ratio presented in Figure 6a for the cortex $(\mathrm{P}<0.001)$ and in Figure $6 \mathrm{~b}$ for the cerebellum $(\mathrm{P}<0.001)$. However, on treatment with RSV, the $\mathrm{Bcl}_{2} /$ Bax ratio was found to be restored to normal levels in both the brain regions of HA rats (Figure $6 \mathrm{a} \& \mathrm{~b}$ ).

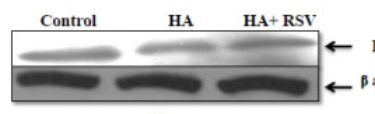

(a)
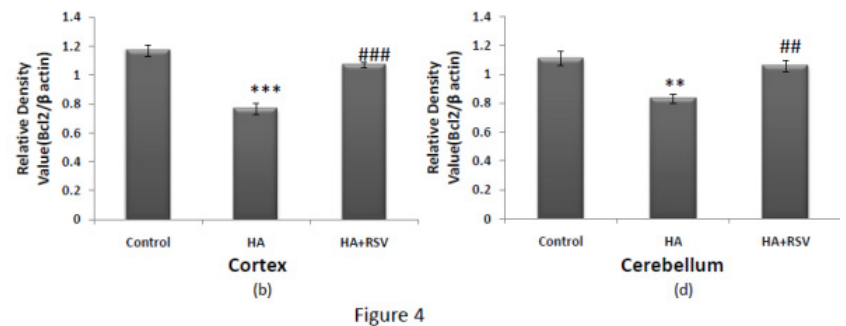

Figure 4 Expression profile of $\mathrm{Bcl}_{2}$ in cerebral cortex (a) and cerebellum (c) of the $\mathrm{HA}$ and $\mathrm{RSV}$ treated $\mathrm{HA}^{2}$ rats. Western blot analysis of $\mathrm{Bcl}_{2}$ was performed as described in the text of methods. The level of $\beta$-actin was taken as the loading control. In panels (b) and (d) normalized densitometric values of $\mathrm{Bcl}_{2} / \beta$-actin for cortex and cerebellum respectively, have been presented as mean \pm SD from three western blot repeats. $* * P<0.0$ I; $* * * P<0.00 I$; (control versus $H A$ rats), $\# \beta<0.01$; \#\# $<0.00$ I (HA versus $H A+R S V$ rats). HA: Hyperammonemia, HA+RSV: Hyperammonemia + Resveratrol.
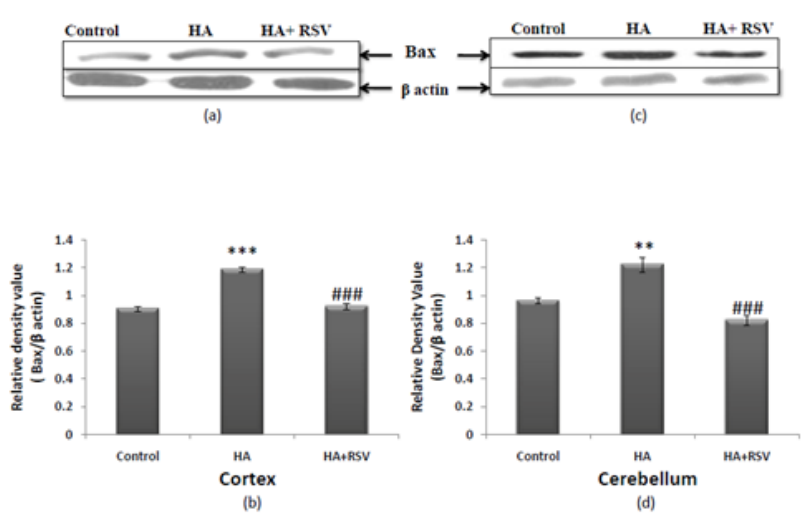

Figure 5 Expression profile of Bax in cerebral cortex (a) and cerebellum (c) of the HA and RSV treated HA rats. Western blot analysis of Bax was performed as described in the text of methods. The level of $\beta$-actin was taken as the loading control. In panels (b) and (d) normalized densitometric values of $\mathrm{Bax} / \beta$-actin for cortex and cerebellum respectively, have been presented as mean $\pm S D$ from three western blot repeats. $\square \square \mathrm{P}<0.01$; $* * * P<0.001$; (control versus $\mathrm{HA}$ rats), \#\#P<0.00I (HA versus $\mathrm{HA}+\mathrm{RSV}$ rats). HA: Hyperammonemia, HA+RSV: Hyperammonemia + Resveratrol.

These findings were further confirmed by conducting the qPCR analysis of $\mathrm{Bcl}_{2}$ and Bax. According to Figure $7 \mathrm{a} \& \mathrm{~b}$, the transcript level of $\mathrm{Bcl}_{2}$ was significantly decreased $(\mathrm{P}<0.01)$ in both the cortex and the cerebellum of the HA rats, as compared to the control group counterparts. This could be normalized in both the brain regions of the HA rats with the resveratrol treatment. Similarly, the transcript level of
Bax, as shown in Figure 8a\&b, was significantly increased $(\mathrm{P}<0.001)$ in both the cortex and the cerebellum of the HA rats, however, due to the RSV treatment, its level recovered to the normal values.
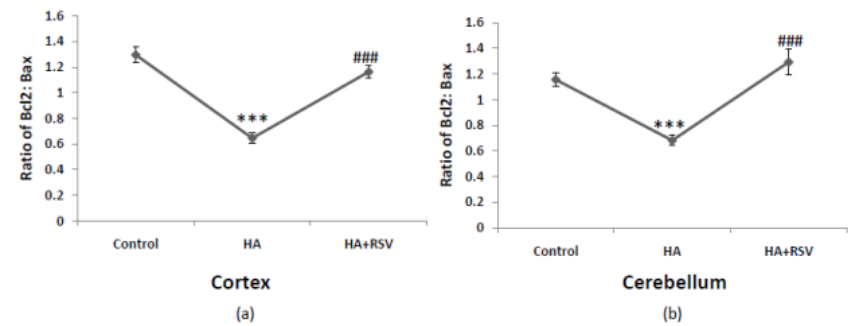

Figure 6 Ratio of $\mathrm{Bcl}_{2} / \mathrm{Bax}$ in cerebral cortex (a) and cerebellum (b) presented as mean $\pm S D$ from three western blot repeats. $* * * P<0.001$; (control versus $\mathrm{HA}$ ) \#P< $0.00 \mathrm{I}$; (HA versus $\mathrm{HA}+\mathrm{RSV}$ rats). HA: Hyperammonemia, HA+RSV: Hyperammonemia + Resveratrol.

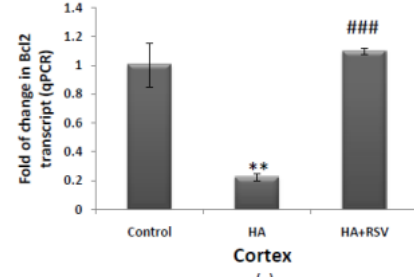

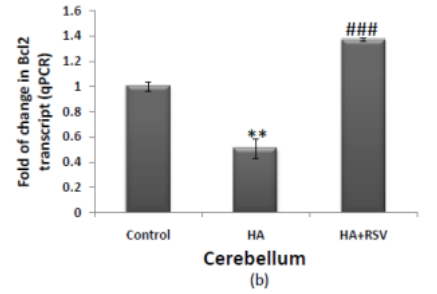

(b)
Figure 7 Expression of $\mathrm{Bcl}_{2}$ gene in cerebral cortex (a) and cerebellum (b) of control, $\mathrm{HA}$ and $\mathrm{HA}+\mathrm{RSV}$ rats. Cycle threshold value of $\mathrm{Bcl}_{2}$ RNA level was normalized with the cycle threshold value of Gapdh for each sample to give a relative quantity of the mRNA expression by $2^{- \text {ddCt }}$. Values are represented as mean \pm SD from 4 repeats; Gapdh was taken as the internal control.

$* * P<0.01$; (control versus HA) \#\#P<0.00I; (HA versus HA+ RSV rats). HA: Hyperammonemia, HA+RSV: Hyperammonemia + Resveratrol.
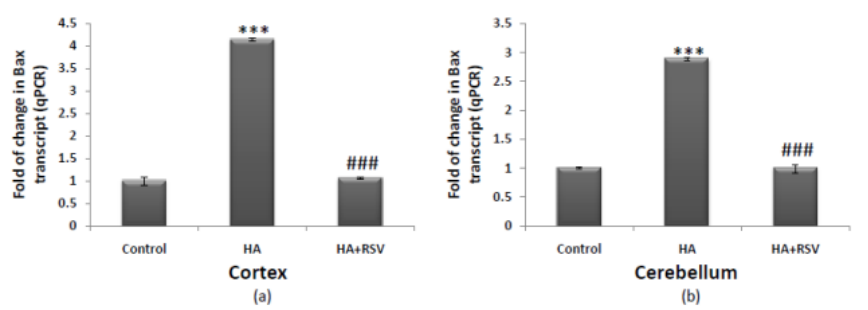

Figure 8 Expression of Bax gene in cerebral cortex (a) and cerebellum (b) of control, HA and HA+RSV rats. Cycle threshold value of Bax RNA level was normalized with the cycle threshold value of Gapdh for each sample to give a relative quantity of the mRNA expression by $2-\mathrm{ddC}$. Values are represented as mean \pm SD from 4 repeats; Gapdh was taken as the internal control. $* * * P<0.00 \mathrm{I}$; (control versus HA) \#\#P<0.00I; (HA versus HA+ RSV rats). HA: Hyperammonemia, HA+RSV: Hyperammonemia + Resveratrol.

Resveratrol is known to exhibit anti-pathogenic activity against a wide range of diseases mainly by acting as a potent ROS scavenger. Moreover, inflammation and ROS generation are now evident to go hand to hand in a number of pathological manifestations, wherein, TNF- $\alpha$ has been found to play a regulatory role. ${ }^{35,36}$ In case of brain disorders also, neuroinflammation and excitotoxicity have been found to be responsible for triggering neuro-excitotoxic disorders/diseases like; traumatic brain injury, Ischemia, Alzheimers disease, Parkinson's disease, etc. ${ }^{17,37-47}$ Recent experimental evidences also suggest that natural antioxidants may modulate the expression of inflammatory cytokines while protecting diseased cells from oxidative insult. For example, fisetin, a natural product has been demonstrated to decrease 
TNF- $\alpha$ mRNA in HCC cells in vivo. ${ }^{48}$ In this article, we examined this hypothesis for RSV, a natural polyphenol, against an inflammation driven excitotoxic brain disorder developed due to persistent $\mathrm{HA}$ in CLF rats.

The enhanced levels of ammonia (Figure 1), in blood and in the two brain regions selected (cortex and cerebellum), represent a moderate grade HA condition exposing brain cells with increased ammonia concentration. And as described earlier, ${ }^{33,49,50}$ these rats were considered to representative of a true CLF led HA model of neuroinflammation/excitotoxicity. Using these HA rats, we examined the expression profiles of TNF- $\alpha, \mathrm{NF} \kappa \mathrm{B}$ and apoptotic factors in the cortex and cerebellum. This is because, these two brain regions have been demonstrated to undergo significant neuro-chemical and neuroanatomical changes during ammonia toxicity and HE pathogenesis..$^{33,50,51}$

The "TNF theory" of HA/HE pathogenesis ${ }^{8}$ emphasizes significant roles of TNF- $\alpha$ and other cytokines in HE up to the extent that these cytokines could be used as markers for encephalopathy grading., $49-13$ Obviously, TNF- $\alpha$ could be considered a suitable target for therapeutic intervention, however, with limited information on its responsiveness towards RSV in neuroinflammation and neuroexcitotoxicity. Modulation of the expression of this cytokine by natural product is an upcoming strategy. ${ }^{48}$ In this respect, results in Figure 2 clearly demonstrate a cause and effect relationship between HA \& TNF- $\alpha$ mRNA level in cerebral cortex and cerebellum of the HA rats and thereby support the TNF- $\alpha$ theory of HA pathogenesis. However, it was interesting to record recovery of TNF- $\alpha$ expression reaching to normal levels due to the in vivo treatment with RSV. Various strategies have been employed to decrease enhanced TNF- $\alpha$ level by blocking its synthesis and enhancing its degradation as therapeutic mechanisms in excitotoxic neurological disorders. ${ }^{17}$ However, examples are limited with regards to RSV and the modulative expression of this cytokine. In this respect, results in Figure 2 are the first of their kind to demonstrate Resveratrol dependent decline in TNF- $\alpha$ mRNA particularly in the cortex and cerebellum of the rats with HA induced neuroinflammation.

The argument gets support from the results in Figure 3 describing $\mathrm{HA}$ dependent similar enhancement in NFKB mRNA level. This is because, $\mathrm{NF \kappa B}$ is known to be a constitutive type transcription factor that is translocated to the nucleus for enhancing expression of the inflammatory cytokines including TNF- $\alpha$ amongst the most prominent ones. ${ }^{12,52,53}$ Moreover, concordant to the RSV dependent decline in TNF- $\alpha$ expression (Figure 3 ), it was interesting to observe a similar recovery in the level of NFKB mRNA in both the brain regions of HA rats treated with RSV. Thus, RSV dependent recovery in the expression of TNF- $\alpha$ and NFKB together, in both the brain regions of HA rats, advocates that RSV could modulate TNF- $\alpha$ level by altering its transcription at gene level. The argument gets support from a recent report describing modulation of TNF- $\alpha$ mRNA by another natural product, fisetin, in case of HCC pathogenesis. ${ }^{48}$

In case of resveratrol, as a neuroprotectant, another issue remaining unsolved is how it prevents possible neurodegeneration under the excitotoxic conditions involving TNF- $\alpha$ as the main culprit. This aspect is equally important because TNF- $\alpha$ is described to inhibit glutamate transport to the glial cells from the synaptic cleft and thereby allowing over activation of glutamate-AMPA and NMDA receptors while decreasing GABA receptor activity of the post synaptic neurons. ${ }^{17}$ Such a situation causes enhanced $\mathrm{Ca} 2+$ entry into the neurons and thereby inducing neuronal death. ${ }^{17}$ Such neuronal deaths then must implicate apoptotic mechanisms to execute safe removal of the dying neurons. The most plausible determinant of intrinsic pathway of apoptosis is the mitochondria damage induced interplay of $\mathrm{Bcl}_{2} /$ Bax ratio under neuropathological conditions. ${ }^{30-32} \mathrm{RSV}$ is known to prevent such neurodegeneration by eliminating the ROS insult ${ }^{12,54,55}$. However, ROS generation and mitochondrial damage also go hand to hand by inducing neurodegenration in acute HA condition. ${ }^{3,50}$ Thus, it is likely that brain cells, particularly, post synaptic neurons, start undergoing apoptosis by involving classical $\mathrm{Bcl}_{2}$-Bax pathways. ${ }^{30-32}$

Moreover, in the present context, the findings in Figure 4,5\& 6 clearly demonstrate a significant decline in $\mathrm{Bcl}_{2} / \mathrm{Bax}$ ratio attributed mainly to the declineing $\mathrm{Bcl}_{2}$ (an antiapoptotic factor) level with the enhanced Bax (pro-apoptotic factor) level in cerebral cortex and cerebellum of the HA rats and thus suggesting induction of apoptosis in both these brain regions of the HA rats. However, when these HA rats were treated with $\mathrm{RSV}$, the $\mathrm{Bcl}_{2} / \mathrm{Bax}$ ratio was found to recover back to normal levels. This further suggests that resveratrol is able to modulate $\mathrm{Bcl}_{2}$ and Bax expression and thereby, allow the recovery of brain cells towards an anti-apoptotic condition from a HA induced pro-apototic microenvironment. This argument gets support from a similar finding on recovery of $\mathrm{Bcl}_{2} / \mathrm{Bax}$ ratio in the cerebellum of CLF rats with even mildest HA condition due to the in vivo treatment with Bacopa extract. ${ }^{51}$ Indeed, Resveratrol could also diminish memory impairment in the vascular dementia model by attenuating increased expression of Bax and declining $\mathrm{Bcl}_{2}$ expression. ${ }^{32}$

\section{Conclusion}

In conclusion, these findings not only provide evidence for a significant neuroprotective role of Resveratrol during moderate grade HA but also demonstrate that it does so by modulating enhanced expressions of $\mathrm{TNF} \alpha$ and $\mathrm{NF \kappa B}$ and by reciprocally regulating expression of $\mathrm{Bax}$ and $\mathrm{Bcl}_{2}$ in the cortex and cerebellum of the HA rats. Unravelling such a mechanistic aspect of in vivo neuroprotective action of resveratrol, under a neuro-excitotxic/neuroinflammation condition, is likely to open up the research for further examination of this mechanism in other brain disorders arising out of neuroinflammation and excitotoxicity.

\section{Acknowledgements}

This work was financially supported by an ICMR project (54/38/ CFPGER/2011/NCD-II) to SKT. A. Khanna acknowledges the Lady Tata Memorial Trust- JRF/SRF' awarded to her during the tenure of this work. The authors are thankful to the DST FIST, CAS COSIST, DST Purse and DBT-BHU ISLS programmes in the Department \& Institute of Science for providing instrumentation facilities.

\section{Conflicts of interest}

Author declares there are no conflicts of interest.

\section{Funding}

None.

\section{References}

1. Blei AT, Cordoba J. The Practice Parameters Committee of the American College of Gastroenterology Hepatic Encephalopathy. Am J of Gastroenterol. 2001;96(7):1968-1976.

2. Bajaj SJ, Wade JB, Sanyal AJ. Spectrum of neurocognitive impairment in cirrhosis: implication for the assessment of hepatic encephalopathy. Hepatology. 2009;50(6):2014-2021. 
3. Felipo V. Hyperammonemia. In: A laztha, N Banik, SK Ray, Editors. Brain and spinal cord trauma. 3rd (edn), Handbook of Neurochemistry and molecular neurobiology. Berlin: Springer; 2009.p.43-69.

4. Felipo V, Urios A, Montesinos E, et al. Contribution of hyperammonemia and inflammatory factors to cognitive impairment in minimal hepatic encephalopathy Metabolic Brain Disorder. 2012;27(1):51-58.

5. Hermenegildo C, Montoliu C, Llansola M, et al. Chronic hyperammonemia impairs the glutamate-nitric oxide-cyclic GMP pathway in cerebellar neurons in culture and in the rat in vivo. Eur $J$ Neurosci. 1998;10(10):3201-3209.

6. Hermenegildo C, Monfort P, Felipo V. Activation of N-methyl-daspartate receptors in rat brain in vivo following acute ammonia intoxication: characterization by in vivo brain microdialysis. Hepatology. 2000;31(3):709-715.

7. Poh Z, Chang PEJ. A Current Review of the Diagnostic and Treatment Strategies of Hepatic Encephalopathy. International Journal of Hepatology. 2012;2012:1-10.

8. Odeh M, Sabo E, Srugo I, et al.Relationship between tumor necrosis factor-alpha and ammonia in patients with hepatic encephalopathy due to chronic liver failure. Ann Med. 2005;37(8):603-612.

9. Odeh M. Pathogenesis of hepatic encephalopathy: the tumor necrosis factor-alpha theory. Eur J Clin Invest. 2007;37(4):291-304.

10. Butterworth RF. Neuroinflammation in acute liver failure: Mechanisms and novel therapeutic targets. Neurochem Int. 2011;59(6):830-836.

11. Butterworth RF. Hepatic encephalopathy: a central neuroinflammatory disorder? Hepatology. 2011;53(4):1372-1376.

12. Bobermin LD, Quincozes-Santos A, Guerra MC, et al. Resveratrol preventsammonia toxicity in astroglial cells. PLoS One. 2012;7(12):e52164

13. Chastre A, Bèlanger M, Beauchesne E, et al. Inflammatory cascade driven by tumor necrosis factor- alpha play a major role in the progression of acute liver failure and its neurological complications. PLoS One. 2012;7(11):e49670.

14. Beattie EC, Stellwagen D, Morishita W, et al. Control of synaptic strength by glial TNFalpha. Science. 2002;295(5563):2282-2285.

15. Beste C, Baune BT, Falkenstein M, et al.Variations in the TNF- $\alpha$ gene $(\mathrm{TNF}-\alpha-308 \mathrm{G} \rightarrow \mathrm{A}$ ) affect attention and action selection mechanisms in a dissociated fashion. Journal of Neurophysiology. 2010;104(5):25232531

16. Santello M, Bezzi P, Volterra A. TNFalpha controls glutamatergic gliotransmission in the hippocampal dentate gyrus. Neuron. 2011;69(5):988-1001.

17. Olmos G, Lladó J. Tumor Necrosis Factor Alpha: A link between neuroinflammation and excitotoxicity Mediatorsof Inflammation. 2014;2014:1-12.

18. Tanabe K, Matsushima-Nishiwaki R, Yamaguchi S, et al. Mechanisms of tumor necrosis factor-alpha-induced interleukin-6 synthesis in glioma cells. J Neuroinflammation. 2010;7:16.

19. Tanabe K, Kozawa O, Iida H. Midazolam suppresses interleukin1betainduced interleukin-6 release from rat glial cells. Journal of Neuroinflammation. 2011;8:68.

20. Shawcross DL, Wright G, Olde Damink SW, et al. Role of ammonia and inflammation in minimal hepatic encephalopathy. Metab Brain Dis. 2007;22(1):125-138.

21. Quincozes-Santos A, Andreazza AC, Nardin P, et al. Resveratrol attenuates oxidative-induced DNA damage in C6 Glioma cells. Neurotoxicology. 2007;28(4):886-891.
22. Quincozes-Santos A, Andreazza AC, Goncalves CA, et al. Actions of redox-active compound resveratrol under hydrogen peroxide insult in C6 astroglial cells. Toxicology In Vitro. 2010;24(3):916-920.

23. Pervaiz S. Resveratrol: from grapevines to mammalian biology. FASEB J. 2003;17(14):1975-1985.

24. Kulkarni SS, Cantó C. The molecular targets of resveratrol. Biochim Biophys Acta. 2015;1852(6):1114-1123.

25. Park EJ, Pezzuto JM. The pharmacology of resveratrol in animals and humans. Biochim Biophys Acta. 2015;1852(6):1071-1113.

26. Delmas D, Jannin B, Latruffe N. Resveratrol: preventing properties against vascular alterations and ageing. Mol Nutr Food Res. 2005;49(5):377-395.

27. Baur JA, Sinclair DA. Therapeutic potential of resveratrol: the in vivo evidence. Nat Rev Drug Discov. 2006;5(6):493-506.

28. Vang O Ahmad N, Baile CA, Baur JA, et al. What is new for an old molecule? Systematic review and recommendations on the use of resveratrol. PLoS One. 2011;6(6):e19881.

29. Bobermin LD, Hansel G, Scherer EB, et al. Ammonia impairs glutamatergic communication in astroglial cells: protective role of resveratrol. Toxicol in Vitro. 2015;29(8):2022-2029.

30. Clementi ME, Pezzotti M, Orsini F, et al. Alzheimer's amyloid betapeptide (1-42) induces cell death in human neuroblastoma via bax/bcl-2 ratio increase: an intriguing role for methionine 35. Biochem Biophys Res Commun. 2006;342(1):206-213.

31. Sun ZK, Yang HQ, Wang ZQ, et al. Erythropoietin prevents PC12 cells from beta-amyloid-induced apoptosis via PI3K/Akt pathway. TranslationalNeurodegeneration. 2012;1:1-7.

32. Sun ZK, Ma XR, Jia YJ, et al. Effects of resveratrol on apoptosis in a rat model of vascular dementia. Exp Ther Med. 2014;7(4):843-848.

33. Singh S, Trigun SK. Activation of neuronal nitric oxide synthase in cerebellum of chronic hepatic encephalopathy rats is associated with upregulation of NADPH-producing pathway. Cerebellum. 2010;9(3):384 397.

34. Lowry $\mathrm{OH}$, Rosebrough NJ, Farr AL, et al. Protein measurement with the Folin phenol reagent. J Biol Chem. 1951;193(1):265-275.

35. Afonso V, Santos G, Collin P, et al. Tumor necrosis factor-alpha downregulates human $\mathrm{Cu} / \mathrm{Zn}$ superoxide dismutase 1 promoter via JNK AP-1 signaling pathway. Free Radic Biol Med. 2006;41(5):709-721.

36. Singh KB, Maurya BK, Trigun SK. Activation of oxidative stress and inflammatory factors could account for histopathological progression of aflatoxin-B1 induced hepatocarcinogenesis in rat. Molecular Cellular Biochemistry. 2015;401(1-2):185-196.

37. Goodman JC, Robertson CS, Grossman RG, et al. Elevation of tumor necrosis factor in head injury. J Neuroimmunol. 1990;30(2-3):213-217.

38. Fillit H, Ding W, Buee L, et al. Elevated circulating tumor necrosis factor levels in Alzheimer's disease. Neurosci Lett. 1991;129(2):318-320.

39. Sharief MK, Hentges R. Association between tumor necrosis factor- $\alpha$ and disease progression in patients with multiple sclerosis. $N$ Engl $J$ Med. 1991;325(7):467-472.

40. Boka G, Anglade P, Wallach D, et al. Immunocytochemical analysis of tumor necrosis factor and its receptors in Parkinson's disease. Neurosci Lett. 1994;172(1-2):151-154.

41. Mogi M, Harada M, Riederer $P$, et al. Tumor necrosis factor- $\alpha$ (TNF- $\alpha$ ) increases both in the brain and in the cerebrospinal fluid from parkinsonian patients. Neurosci Lett. 1994;165(1-2):208-210.

42. Feuerstein GZ, Liu T, Barone FC. Cytokines, inflammation, and brain injury: role of tumor necrosis factor-alpha. Cerebrovasc Brain Metab Rev. 1994;6(4):341-360. 
43. Liu T, Clark RK, McDonnell PC, et al. Tumor necrosis factor- $\alpha$ expression in ischemic neurons. Stroke. 1994;25(7):1481-1488.

44. Rieckmann P, Albrecht M, Kitze B, et al. Tumor necrosis factor- $\alpha$ messenger RNA expression in patients with relapsing-remitting multiple sclerosis is associated with disease activity. Ann Neurol. 1995;37(1):8288 .

45. Poloni M, Facchetti D, Mai R, et al. Circulating levels of tumour necrosis factor- $\alpha$ and its soluble receptors are increased in the blood of patients with amyotrophic lateral sclerosis. Neurosci Lett. 2000;287(3):211-214.

46. Alvarez A, Cacabelos R, Sanpedro C, et al.Serum TNF-alpha levels are increased and correlate negatively with free IGF-I in Alzheimer disease. Neurobiol Aging. 2007;28(4):533-536.

47. Babu GN, Kumar A, Chandra R, et al. Elevated inflammatory markers in a group of amyotrophic lateral sclerosis patients from northern India. Neurochem Res. 2008;33(6):1145-1149.

48. Maurya K, Trigun SK. Fisetin Modulates Antioxidant Enzymes and Inflammatory Factors to Inhibit Aflatoxin-B1 Induced Hepatocellular Carcinoma in Rats. Oxidative Medicine and Cellular Longevity. 2016;2016(2016):1-9.
49. Felipo V, Butterworth R. Neurobiology of ammonia. Prog Neurobiol. 2002;67(4):259-279.

50. Singh S, Trigun SK. Low grade cirrhosis induces cognitive impairment and motor dysfunction in rats: Could be a model for minimal hepatic encephalopathy. Neurosci Lett. 2014;559:136-140.

51. Mondal P, Trigun SK. Bacopa monnieri Extract (CDRI-08) Modulates the NMDA Receptor Subunits and nNOS-Apoptosis Axis in Cerebellum of Hepatic Encephalopathy Rats. Evid Based Complement Alternat Med. 2015;2015:535013.

52. Baltimore D. NF-kappaB is 25. Nature Immunology. 2011;12:683-685.

53. Gerlo S, Kooijman R, Beck IM, et al. Cyclic AMP: a selective modulator of NF-kappaB action. Cell Mol Life Sci. 2011;68(23):3823-3841.

54. Shen HM, Pervaiz S. TNF receptor superfamily-induced cell death: redox-dependent execution. FASEB J. 2006;20(10):1589-1598.

55. Hamby ME, Gragnolati AR, Hewett SJ, et al.TGF beta 1 and TNF alpha potentiate nitric oxide production in astrocyte cultures by recruiting distinct subpopulations of cells to express NOS-2. Neurochem Int. 2008;52(6):962-971. 